\title{
PERFIL EPIDEMIOLÓGICO E COMPLICAÇÕES AGUDAS EM PACIENTES TRANSPLANTA- DOS RENAIS DO ESTADO DO ACRE
}

\author{
Epidemiological profile and acute complications in kidney transplant recipients of Acre's state
}

\author{
Giorge Pereira Sampaio, Mariane Rodrigues Wanderley, Solino Matos Neto, Danilo Feliphe Valeiro, Nilton Ghiotti de Siqueira
}

\begin{abstract}
RESUMO
O transplante renal foi o primeiro procedimento largamente utilizado no tratamento de falência terminal de órgãos. Atualmente, o Brasil possui o maior sistema público de transplantes de órgãos e tecidos, encontrando-se em segundo lugar na realização desse procedimento, atrás apenas dos Estados Unidos. O transplante renal é o tratamento de escolha para pacientes com insuficiência renal crônica terminal, quando não apresentam contra-indicação, por ser, das formas de substituição da função renal, a que oferece melhor reabilitação com o menor custo social. Objetivos: Este estudo visa descrever o perfil social e clínico dos pacientes transplantados renais, assim como abordar as complicações surgidas no período de internação pós-transplante no Hospital das Clínicas do Acre. Métodos: Para alcançar esses objetivos foram realizadas consultas aos prontuários dos pacientes submetidos ao transplante de rim no período entre janeiro de $2010 \mathrm{e}$ junho de 2011, no Hospital das Clínicas do Acre. Resultados: Dos 15 pacientes transplantados nesse período, a maioria (nove) era do sexo masculino. A média de idade foi de 29,87, com mínimo de 15 e máximo de 65 anos de idade. A maior parte dos pacientes era proveniente de Rio Branco/AC. Três pacientes tiveram complicações, porém não houve nenhuma rejeição de enxerto. Conclusão: o estudo proporcionou maior conhecimento da realidade dos pacientes transplantados no Estado do Acre e poderá contribuir para o aperfeiçoamento do cuidado ao paciente em fila de espera para transplante e pós-transplantado renal.
\end{abstract}

Descritores: Transplante; Rim; epidemiologia; complicações.

\section{INTRODUÇÃO}

O transplante renal foi o primeiro tratamento largamente utilizado para a falência terminal de órgãos. As técnicas cirúrgicas básicas são as mesmas desenvolvidas no princípio do século XX, por Alexis Carrel, ganhador do prêmio Nobel de 1912. ${ }^{1}$ $\mathrm{O}$ primeiro transplante inter vivos com sucesso no mundo foi realizado no ano de 1954, por Murray e John Merrill, entre gêmeos monozigóticos. A sobrevida do paciente transplantado foi de oito anos, com função renal satisfatória. ${ }^{2}$ Atualmente, o Brasil possui o maior sistema público de transplantes de órgãos e tecidos do mundo, encontrando-se em segundo lugar na realização desse procedimento, atrás apenas dos Estados Unidos. Segundo o Ministério da Saúde, em maio de 2005, 62.785 doentes esperavam por um transplante. ${ }^{3}$

\section{Instituição:}

Centro de Ciências da Saúde e do Desporto da Universidade Federal do Acre - Rio Branco/AC, Brasil

\section{Correspondência:}

Giorge Pereira Sampaio

Avenida Norte, 429 / 03, Conjunto Tucumã II, CEP 69.917-400, Rio Branco/AC

Fone: (68) 3229-1135

E-mail: giorgesampaio@hotmail.com

A causa mais comum de insuficiência renal crônica (IRC) é o diabetes mellitus, seguido de hipertensão arterial, glomerulonefrite e doença renal cística, culminando em falência renal, confirmada por taxas de filtração glomerular inferior a $10 \mathrm{ml} / \mathrm{min}$ ou nível sérico de creatinina superior a $8,0 \mathrm{mg} / \mathrm{dl} .^{4}$ Os princípios gerais do transplante incluem o conceito de que o paciente tenha benefício com o transplante em relação à diálise, à expectativa de vida de pelo menos cinco anos e que ele seja capaz de tolerar a intervenção cirúrgica, o estresse pós-operatório e as complicações, em longo prazo, associadas à imunossupressão., O procedimento pode ser retardado, enquanto o paciente realiza hemodiálise ou diálise peritonial, e realizado no momento mais apropriado ou pode ser realizado no momento em que a função renal 
declina significativamente e se planeja início da terapia substitutiva nos meses seguintes, já que o transplante renal oferece maior expectativa de vida para pacientes com idade abaixo dos 40 anos. $^{7}$

As contra-indicações, além da recusa do paciente em realizar o transplante, são: infecção ativa, etilismo, presença de neoplasia metastática, condições que limitam gravemente a expectativa de vida, a não-aderência que implique risco de não utilizar as medicações imunossupressoras, complicações da imunossupressão inaceitáveis para o paciente, AIDS, exceto nos casos em que: a contagem de CD4 for maior que 200 céls $/ \mathrm{mm}^{3}$ por mais de seis meses, níveis indetectáveis de HIV-1 RNA, terapia anti-retroviral estável por mais de três meses, sem outras complicações da doença.

$\mathrm{Na}$ avaliação, além da história e do exame físico, o paciente é submetido a um conjunto de exames (tabela 1). Entre as avaliações de rotina estão incluídas a odontológica, a ginecológica para as mulheres e a urológica para os homens com mais de 45 anos, incluindo PSA e avaliação da próstata. $^{8}$

Tabela 1. Investigação Básica do Receptor

$\begin{array}{lcc}\text { Tipagem sanguínea } & \text { HbsAg } & \text { EBV } \\ \text { e HLA } & \text { Anti-HBc (IgM e IgG) } & \text { Varicela-zóster } \\ \text { Hemograma } & \text { Anti-Hbs } & \text { Reação de Mantoux } \\ \text { Glicemia } & \text { Anti-HCV } & \text { Urocultura } \\ \text { Colesterol e frações } & \text { Anti-HIV } & \text { DCE, Proteinúria 24h } \\ \text { Triglicerídeos } & \text { CMV } & \text { TP, TTPA } \\ \text { AST, ALT, GGT } & \text { VDRL } & \text { Plaquetas } \\ \text { Bilirrubinas } & \text { Toxoplasmose } & \text { Raio-x de tórax } \\ \text { Fosfatase alcalina } & \text { Chagas } & \text { Eletrocardiograma } \\ \text { Cálcio iônico, Fósforo } & \text { HTLV-1 e 2 } & \text { Ecografia abdominal } \\ \text { Albumina } & & \end{array}$

HLA = Antígeno leucocitário humano. $\mathrm{HbsAg}=$ Antígeno de superfície da Hepatite $\mathrm{B} ; \mathrm{EBV}=$ Vírus Epstein-Barr; Anti-HBc = Anticorpo dirigido contra as proteínas do core ou nucleocapsídeo do vírus da Hepatite $B ;$ Anti-Hbs = Anticorpos contra 0 antígeno de superfície do vírus da Hepatite B; Anti-HCV = Anticorpos contra 0 antígeno do vírus da Hepatite $\mathrm{C}$; Anti-HIV = Anticorpos contra o antígeno do vírus da Imunodeficiência Humana; DCE = Depuração de creatinina endógena; $A S T$ = Aspartato aminotransferase; $A L T=$ Alanino aminotransferase.;GGT = Gama glutamiltransferase; $\mathrm{CMV}=$ Citomegalovírus; $\mathrm{TP}=$ Tempo de protrombina; TTPA = Tempo de tromboplastina parcialmente ativada; $\mathrm{VDRL}=$ Venereal disease research laboratory; HTLV = Vírus T-linfotrópico humano.

A idade é um fator importante a ser considerado, pois crianças com menos de cinco anos constituem o grupo etário com pior sobrevida. ${ }^{9}$ Adolescentes, por apresentarem risco alto de não aderência ao tratamento, necessitam de acompanhamento familiar constante e especial atenção para a avaliação biológica. ${ }^{10}$

A interrupção do hábito de fumar deve ser uma das condutas da avaliação pré-transplante renal, pois a sobrevida é menor entre os pacientes ex-fumantes, mas pior ainda nos fumantes ativos. ${ }^{11}$

Estudos recentes apontam que os riscos do receptor com IMC $>30$ $\mathrm{kg} / \mathrm{m}^{2}$ são mínimos. Entretanto, os programas de transplante renal costumam evitar receptores obesos ou exigir a redução de peso no pré-transplante. ${ }^{12}$

A doença cardiovascular é a principal causa de morte dos pacientes em liza diálise ou transplantados renais. ${ }^{13}$
As doenças diagnosticadas devem ser tratadas antes do transplante, visando prevenir complicações perioperatórias e melhorar o prognóstico em longo prazo. ${ }^{14}$

A existência de neoplasia contra-indica o transplante, entretanto, pacientes submetidos a tratamento curativo podem ser considerados candidatos a transplante se não apresentarem evidência de doença ativa após um prazo de dois a cinco anos..$^{15,16}$

A presença de infecção ativa é contra-indicação absoluta para realização do transplante renal, sendo imperativo o tratamento do processo infeccioso antes da cirurgia. Por esse motivo, nos candidatos a transplante renal é necessária uma meticulosa busca por focos infecciosos. ${ }^{17}$

A trombose dos vasos renais, apesar de pouco frequente, responde, atualmente, pela maioria das enxertectomias no primeiro mês após o transplante. ${ }^{18}$

A trombose de artéria renal é uma complicação pouco frequente, manifestando-se, em geral, no primeiro mês após o transplante. ${ }^{19}$ A maioria das séries relata uma incidência de cerca de $2 \%{ }^{20}$ Vários fatores são associados à trombose de artéria renal como: erro de técnica, hipotensão nos pós-operatório, rejeição, períodos excessivos de isquemia, utilização de doadores de idades limítrofes, enxertos com múltiplas artérias e doença vascular do receptor. ${ }^{21}$

Outra complicação, a estenose da artéria renal, geralmente tende a se manifestar mais tardiamente (semanas e anos após o transplante) e a incidência é muito variável (de 1,6\% a 11,5\%). Quando ocorre distalmente à anastomose, ou seja, somente na artéria renal do enxerto, está associada à rejeição crônica ou à lesão de íntima durante o processo de retirada. ${ }^{22}$ Estenose na artéria ilíaca do receptor quase sempre resulta de doença aterosclerótica prévia ao transplante. ${ }^{23}$

A trombose de veia renal é uma complicação um pouco mais frequente que a trombose da artéria (ocorre em até $6 \%$ dos casos). Pode estar associada a erros de técnica, como veia excessivamente longa, torção, desproporção no calibre dos vasos, sutura inadequada da veia com estenose, uso de enxerto venoso e presença de mais de uma veia renal. ${ }^{24}$

Hematomas perirrenais geralmente são diagnosticados nos primeiros dias de pós-operatório e são relativamente frequentes. Podem ocorrer em virtude de distúrbios da coagulação, hemostasia inadequada do enxerto, heparinização associada à hemodiálise no pré-transplante ou no pós-operatório, crise hipertensiva e após biópsia renal. ${ }^{25} \mathrm{O}$ paciente pode apresentar instabilidade hemodinâmica, palidez, dor, aumento súbito de volume do enxerto ou sangramento pela incisão. ${ }^{26}$

A incidência de infecção de ferida operatória em transplantados pode variar de $1 \%$ a $10 \%$ dos pacientes. ${ }^{27} \mathrm{O}$ diagnóstico deve ser feito precocemente, a incisão aberta e o material colhido enviado para cultura e anti-biograma. ${ }^{28}$ A terapia com antibióticos deve ser iniciada imediatamente e confirmada com a cultura e o teste de sensibilidade aos antibióticos. ${ }^{29}$

Linfoceles são detectadas em até $18 \%$ dos pacientes submetidos a transplante renal. A linfa pode originar-se dos vasos linfáticos que circundam os vasos ilíacos, seccionados por ocasião do transplante, e não-ligados adequadamente. ${ }^{30}$ Pode também ter a sua origem nos vasos linfáticos localizados no hilo renal e nas lacerações do parênquima renal, especialmente durante processos de rejeição aguda, em que o fluxo linfático aumenta consideravelmente. ${ }^{31}$ 
As fístulas urinárias podem ocorrer desde os cálices renais até a bexiga, sendo as fístulas ureterais distais as mais frequentes. Via de regra, são decorrentes de má técnica na uretero-neocistostomia ou na remoção e cirurgia de banco, em virtude da excessiva dissecção junto ao hilo renal e consequente isquemia. ${ }^{32}$

A litíase urinária tem uma incidência de $0,9 \%$ a 1,5\%.33 Os cálculos podem desenvolver-se após o transplante ou ser transplantados inadvertidamente, sendo essa última situação mais provável para doadores falecidos. Tipicamente, o cálculo apresenta-se com obstrução aguda e disfunção do aloenxerto ou como infecção urinária. ${ }^{33}$

A obstrução ureteral tem como etiologias mais frequentes: isquemia, coágulos na luz ureteral, erro de técnica ou edema importante no implante ureteral e estenose preexistente na junção ureteropélvica do aloenxerto. Tardiamente, as causas mais comuns de obstrução recaem sobre rejeição crônica e fibrose periuretral. A incidência de obstrução ureteral é $1,3 \%$ a $10,2 \%{ }^{34}$

O Centro de Transplantes do Acre realiza transplantes renais desde 2006, sendo que no ano de 2009 o programa foi interrompido por problemas institucionais, tendo sido retomado em 2010. Desde a implantação do programa de transplantes renais até o ano de 2010 foram realizados 21 transplantes, sendo três no ano de 2006, quatro no ano de 2007, dois no ano de 2008 e 12 no ano de 2010. Desse total, 19 transplantes tiveram doadores vivos e dois, doadores falecidos (dezembro de 2010). Até o presente momento, pouco se conhece a respeito dos pacientes cujos transplantados renais foram realizados nessa instituição. Desta forma, este estudo, cuja importância é epidemiológica, tem como objetivos traçar o perfil clínico e social dos pacientes transplantados, avaliar as principais indicações dos transplantes, o tempo de espera para doação e as complicações agudas durante o período de internação póstransplante em pacientes submetidos a transplante renal no período de janeiro de 2010 a junho de 2011 no Hospital das Clínicas do Acre.

\section{MÉTODOS}

O estudo referido foi realizado na capital do Estado do Acre, Rio Branco. O Estado é parte integrante da Amazônia e está localizado na região norte do país. Rio Branco é hoje o município mais populoso do Estado. Possui extensão de $152.588 \mathrm{~km} 2$, fazendo fronteira com dois países, Bolívia e Peru. A flora é típica de floresta tropical úmida e o relevo é formado por largas planícies. Sua população total é aproximadamente 707.125 habitantes. Rio Branco está dividido em duas mesorregiões: Vale do Juruá e Vale do Acre. O município de Rio Branco localiza-se na mesorregião do Vale do Acre.

O presente estudo foi realizado no Hospital das Clínicas do Acre.

O Hospital é composto por:

- $\quad$ Enfermaria de Infectologia (A);

- $\quad$ Enfermaria de Clínica Médica (B);

- $\quad$ Enfermaria de Cirurgia (C);

- $\quad$ Enfermaria de Ginecologia e Ortopedia (D);

- $\quad$ O Hospital do Idoso;

- Unidade de alta complexidade em oncologia (UNACON).

O Hospital das Clínicas possui quarenta e oito quartos, um quarto possui cinco leitos, três quartos possuem dois leitos e, quarenta e quatro possuem quatro leitos. A enfermaria D é distribuída em quarenta e nove leitos. Desses, dois são áreas de isolamento e dois são destinados para cirurgias variadas. Ao final dessa enfermaria, existem quatro leitos (área restrita) exclusivos aos pacientes transplantados renais.

A população alvo foi composta pelos pacientes submetidos a transplante renal no Hospital das Clínicas do Acre, no período de janeiro de 2010 a junho de 2011.

O estudo realizado é de caráter institucional, transversal, quantitativo e de base populacional.

A amostra foi composta por todos os pacientes de transplante de rim pelo Centro de Transplante do Acre, no período entre janeiro de 2010 e junho de 2011, tendo sido feita a partir de consulta aos prontuários uma vez ao mês, durante dezoito meses.

Foram analisados dados referentes à idade dos pacientes, etnia, sexo, IMC, procedência, a doença que originou a Insuficiência Renal Crônica Terminal, co-morbidades, tempo de espera para o transplante renal, tempo de internação, as complicações agudas durante o período de internação pós-transplante, pressão arterial no pós-operatório, rejeição do enxerto, idade do doador, tempo de hemodiálise pré-transplante, função retardada do enxerto renal (esta se baseia na necessidade de hemodiálise na primeira semana após o transplante), creatinina na alta hospitalar, imunossupressão utilizada e os respectivos níveis terapêuticos.

$\mathrm{Na}$ análise estatística do estudo não foi realizada inferência estatística, visto que toda a população de transplantados renais foi alvo de estudo, certificando-se da significância de ordem prática para as afirmações que poderão ser inferidas. Os dados obtidos foram colocados em um gerenciador de banco de dados para, posteriormente, serem analisados estatisticamente pelo software SPSS $^{\text {TM }}$ (Statistical Package for the Social Sciences) versão 9.0 para Windows.

$\mathrm{O}$ estudo foi iniciado depois de encaminhado e aprovado pelo Comitê de Ética e Pesquisa (CEP) do Hospital das Clínicas do Acre, com parecer favorável de no 531/2011.

\section{RESULTADOS}

Havia 15 pacientes transplantados no período de janeiro de 2010 a junho de 2011 no Hospital das Clínicas do Acre. A média de idade dos pacientes transplantados era de 29,87 , com mínimo de 15 e máximo de 65 anos de idade. Todos os indivíduos eram de etnia parda. Nove transplantados eram do sexo masculino, sendo esse o sexo mais prevalente; já do sexo feminino, eram seis transplantados (Figura 1).

Figura 1. Prevalência de gênero dos pacientes transplantados

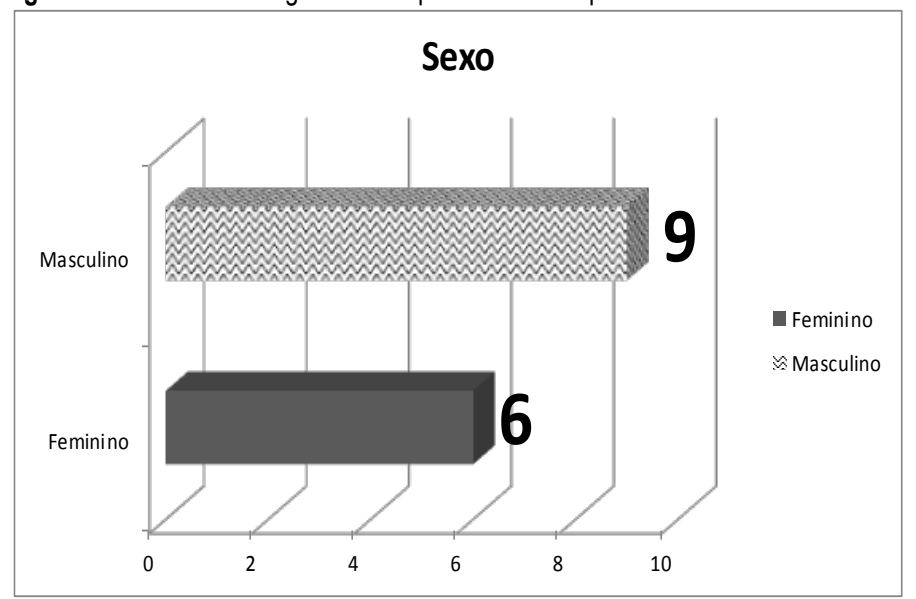


A média do índice de massa corpórea (IMC) foi de $22,98 \mathrm{Kg} /$ $\mathrm{m} 2$ com o máximo de $31 \mathrm{Kg} / \mathrm{m} 2$ e o mínimo de $15 \mathrm{Kg} / \mathrm{m} 2$. A procedência dos pacientes transplantados foi prevalente da capital do Acre, Rio Branco, com 11 pacientes e do interior foram quatro pacientes, sendo dois de Feijó, um de Sena Madureira e um de Assis Brasil. Em relação à doença de origem, $60 \%$ (nove) tinham nefroesclerose hipertensiva e $40 \%$ (seis), glomerulonefrite (Figura 2). A hipertensão arterial sistêmica foi uma comorbidade presente em todos pacientes transplantados.

Figura 2: Prevalência de doenças que originaram a Insuficiência Renal Crônica.

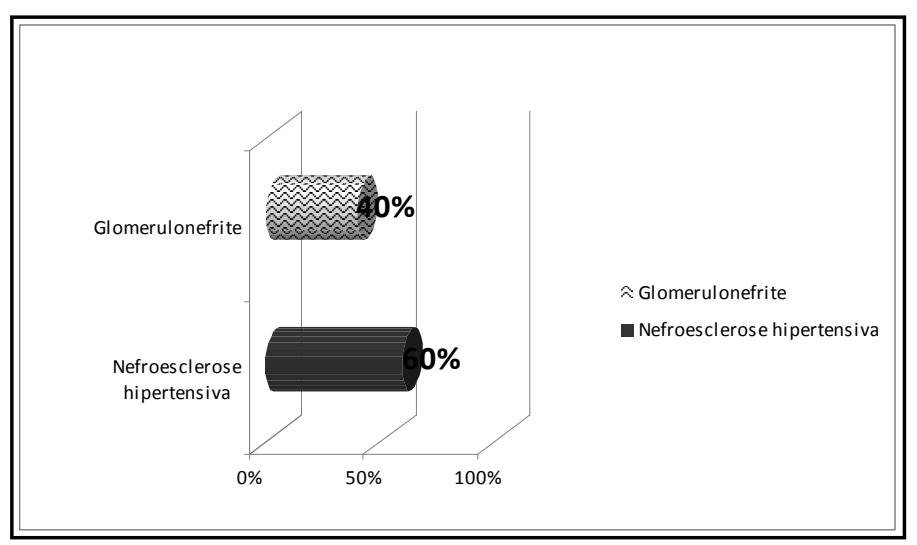

A média do tempo de espera em lista para transplante foi de 7,08 meses com mínimo de 10 dias e máximo de 13 meses. O tempo médio de internação foi de 10,13 dias, com mínimo de sete dias e máximo de 23 dias. Apenas dois transplantados receberam o órgão de doador falecido (Figura 3), o qual tinha 14 anos.

\section{Figura 3: Tipos de doadores de rim}

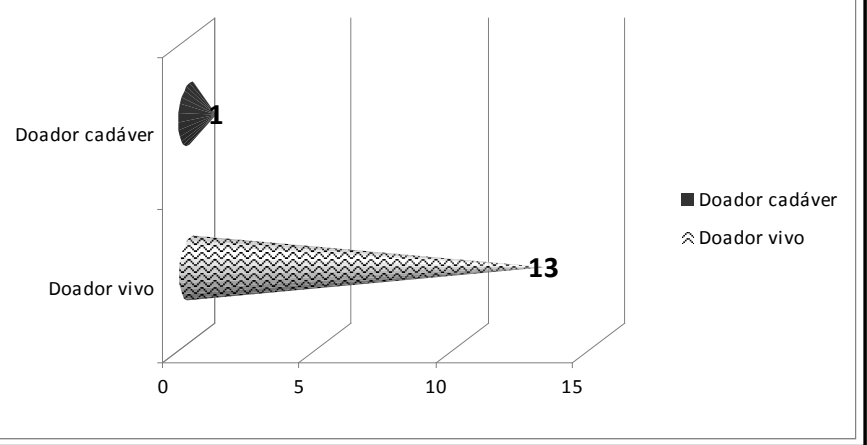

A média de idade do doador foi de 33,2 anos, com mínimo de 14 anos e máximo de 51 anos de idade. Em 80\% dos transplantados não houve nenhuma complicação aguda. Foram encontradas somente três complicações, sendo uma linfocele, um reimplante de ureter e uma ressecção transuretral de próstata (Figura 4).
Figura 4. Prevalência de complicações no período imediato pós-transplante.

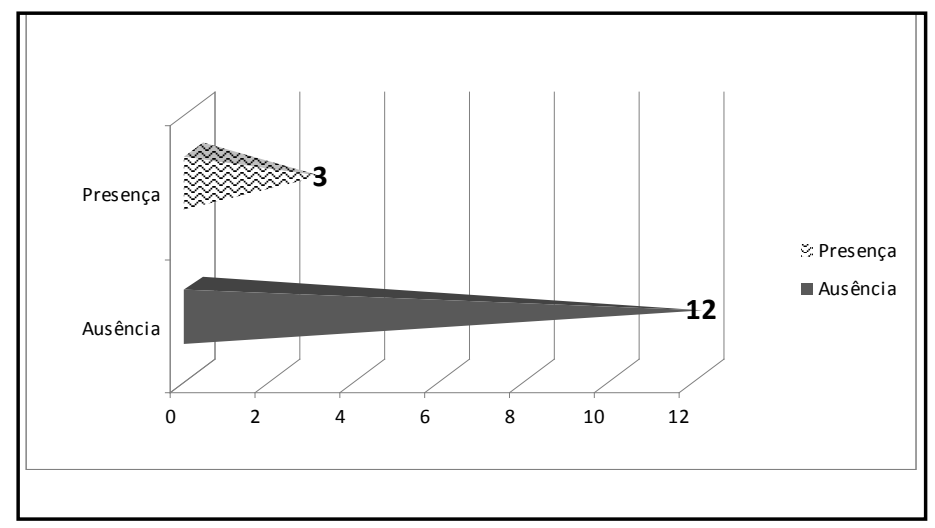

Todos fizeram hemodiálise antes do transplante, onde o tempo médio de diálise era de 27,13 meses, com mínimo de oito dias e máximo de cinco anos e nove meses. Apenas um paciente necessitou fazer hemodiálise no pós-operatório (figura 5), sendo necessária uma sessão. Dos que apresentaram complicação aguda, somente um apresentou hipertensão no pós-operatório, tendo sido uma senhora de 60 anos, procedente de um município do interior, a qual apresentava como doença de base uma nefroesclerose hipertensiva e um índice de massa corpórea de $31,13 \mathrm{Kg} / \mathrm{m} 2$. No pós-operatório, foi necessário realizar heparinização e hemodiálise.

\section{Figura 5: Função retardada do enxerto renal}

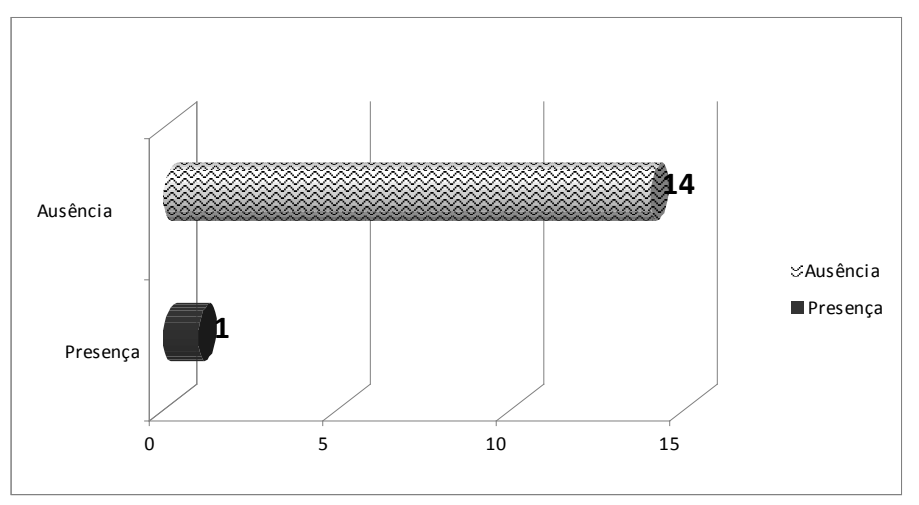

Foram submetidos à heparinização somente dois, sendo um, a paciente relatada acima e outro, um homem de 65 anos de idade. Para esse último, o tempo de internação foi o mais longo (23 dias, com tempo de espera de nove meses). Nenhum paciente teve rejeição do enxerto. A creatinina, na alta hospitalar, mostrou-se com o valor mínimo de $0,8 \mathrm{mg} / \mathrm{dl}$ e o valor máximo de $5,0 \mathrm{mg}$ / $\mathrm{dl}$, cuja média dos pacientes estudados foi de $1,87 \mathrm{mg} / \mathrm{dl}$. O Micofenolato de Mofetila, Tacrolimo e Prednisona foram as drogas de imunossupressão utilizadas em todos os pacientes. A média dos níveis terapêuticos foi de $9,46 \mathrm{ng} / \mathrm{ml}$, em que o valor mínimo foi de $3,6 \mathrm{ng} / \mathrm{ml}$ e o valor máximo foi de $14,9 \mathrm{ng} / \mathrm{ml}$. 


\section{DISCUSSÃO}

A média de idade dos pacientes submetidos à terapia renal substitutiva (TRS) no presente estudo foi substancialmente menor, comparada àquela encontrada por Cherchiglia et al. ${ }^{35} \mathrm{O}$ grande número de pacientes jovens no estudo favorece a hipótese descrita por Cunha et al., ${ }^{36}$ quando afirma que os idosos teriam menos chances de ser transplantados.

O maior número de transplantados do sexo masculino pode ser apenas resultado do fato desse ser o gênero predominante nos pacientes com insuficiência renal crônica terminal e que fazem uso de terapia renal substitutiva (57\%), como já demonstrado por Sesso. ${ }^{37} \mathrm{O}$ achado relacionado à etnia dos pacientes não possui relevância estatística pelo pouco número de pacientes do estudo e pela diversidade étnica da região onde os pardos compõem a maioria da população segundo o censo 2010 do IBGE.

O fato de Estudante ter sido a profissão mais encontrada, responsável por praticamente metade dos pacientes $(46,6 \%)$, pode ser explicado ao olharmos a baixa faixa etária dos indivíduos submetidos ao transplante renal. Atividades voltadas ao cuidado do lar representam $20 \%$ das profissões do estudo. Nenhuma outra profissão mereceu destaque. $73 \%$ dos transplantados renais eram procedentes da capital do Acre, Rio Branco.

Essa maioria deve-se à maior facilidade de acesso ao sistema, o que pode significar uma possível subestimação dos casos de insuficiência renal crônica (IRC) no Estado que conseguem ter atendimento médico, seja por dificuldades logísticas, financeiras ou por falta de informação.

A média do índice de massa corpórea (IMC) foi abaixo de $30 \mathrm{Kg}$ / $\mathrm{m}^{2}$, o que deixaria reduzido o risco de complicações em pacientes submetidos ao transplante renal pelo alto peso, excetuando-se uma paciente com IMC de $31,13 \mathrm{Kg} / \mathrm{m}^{2}$, que apresentou complicações pós-operatórias descritas logo a seguir.

Em alguns países da América Latina e em grande parte dos países desenvolvidos, a causa mais freqüente de doença renal crônica (DRC) é o diabetes mellitus. Entretanto, neste estudo, as duas causas relacionadas à DRC entram em conformidade com os relatados por Sesso ${ }^{37}$ e Santos ${ }^{38}$, porém em desacordo com Cunha et al., ${ }^{36}$ Morsch et al ${ }^{39}$ e D'Ávila et al. ${ }^{40}$

O tempo médio de espera para realização do procedimento foi substancialmente inferior ao tempo encontrado por Machado et al.(2,2 anos). ${ }^{41}$ A porcentagem de rins obtidos de doadores postmortem foi muito inferior àquela divulgada pelo mesmo autor $(46,3 \%)$. Ambas as situações denotam possíveis dificuldades encontradas durante a implantação do serviço de TRS e deficiências no sistema de captação de órgãos do estado do Acre.

Cabe ainda ressaltar que um estudo de Lopes et al. ${ }^{42}$ evidenciou maior risco associado à estenose de artéria renal em transplante com rim de doador falecido.

A idade do doador é uma das variáveis que possui maior impacto estatístico na sobrevida dos transplantes renais. Uma média de ${ }^{33,2}$ anos está dentro do esperado segundo Cassini, ${ }^{43}$ onde a sobrevida foi maior entre os doadores que possuíam menos de 40 anos.
Dos quinze pacientes submetidos ao transplante, nove apresentaram hipertensão no pós-operatório imediato, sendo que apenas um deles cursou com complicações agudas. A pressão arterial elevada no pós-operatório está relacionada com maiores chances de complicações vasculares, segundo a Sociedade Brasileira de Nefrologia e Urologia. ${ }^{44} \mathrm{O}$ tempo de internação médio foi 10,3 dias. Todos os pacientes foram submetidos à hemodiálise pré-transplante e o tempo médio de diálise antes do transplante evidencia um ponto positivo que é a maior velocidade entre a entrada na lista e o transplante renal, diferente do descrito por Machado et al. ${ }^{41}$.

O tempo de atividade da protrombina (TAP) dos pacientes estava entre 12 e 14,4 segundos, nunca abaixo do limite de normalidade, entrando de acordo com os princípios pré-operatórios de uma cirurgia eletiva como o transplante renal. Quanto à contagem de plaquetas, nenhum paciente estava com níveis acima de 300.000 e dois apenas apresentavam menos de 150.000 de trombócitos e não estavam associados a complicações agudas, sendo que um deles apenas apresentou hipertensão no pós-operatório.

A única paciente que necessitou realização de diálise póstransplante cursou com uma linfocele. É importante lembrar que, embora seja uma complicação relativamente comum, linfoceles podem ter como etiologia a rejeição aguda, segundo estudo da Sociedade Brasileira de Nefrologia e Urologia. ${ }^{44}$ As outras duas complicações foram o reimplante de ureter e a ressecção transureteral de próstata.

No caso do reimplante de ureter, tratava-se de paciente do sexo feminino, 36 anos, IMC de 22,2 Kg/m², 10 meses de espera para transplante, coagulograma normal, com três anos e dez meses de diálise, normotensa no pós-operatório. Tal procedimento geralmente é feito quando há evidência de fístula urinária por problema na implantação uretero-vesical ou por necrose de ureter. $\mathrm{O}$ curso da primeira é geralmente melhor que a segunda, sempre associando o reimplante com derivação urinária (duplo jota) segundo a Sociedade Brasileira de Nefrologia e Urologia. ${ }^{44} \mathrm{O}$ caso da ressecção transureteral de próstata ocorreu em um paciente de 65 anos, IMC de $24,3 \mathrm{Kg} / \mathrm{m}^{2}$, com tempo de diálise de dois anos e seis meses, e nove meses de tempo de espera para o transplante, com exames laboratoriais dentro da normalidade, normotenso no pós-operatório.

\section{CONCLUSÃO}

Por fim, esses achados proporcionaram um maior conhecimento da realidade dos pacientes transplantados no Estado e podem contribuir para o aperfeiçoamento do cuidado ao paciente em fila de espera para transplante e pós-transplantado renal.

$\mathrm{O}$ índice de complicações agudas baixo pode ser resultado do fato de casos de IRC mais arrastados e com maior risco de morte serem encaminhados para realização de transplante em outro Estado com maior aporte técnico.

É importante ressaltar a necessidade de estudos posteriores no que diz respeito ao acompanhamento em longo prazo (pelo menos cinco anos) dos transplantados renais, com análise de qualidade de vida, complicações tardias, função renal e aderência ao tratamento imunossupressor. 


\title{
ABSTRACT:
}

Kidney transplantation was the first procedure used to treat terminal failure organs. Nowadays Brazil has the biggest public system of organ and tissue transplantation, being in the second place in such proceeding behind the United States of America. Kidney transplantation is the choice to patients with kidney's terminal chronic insufficiency; it has no counter indication, since it offers best rehabilitation with few socials costs. Purpose: This study describes social and clinical profile of kidney transplantation patients, and it approaches complications arisen in post-transplantation confinement in Hospital das Clínicas do Acre. Methods: In order to get these objectives, it was performed consultations on the medical registers of all patients submitted to kidney transplantation between January 2010 and June 2011 at Hospital das Clínicas do Acre. Results: Fifteen patients were transplanted during such period being the majority (nine) male. The average age was 29.87, being fifteen the minimum and 65 years the maximum age. The majority was from Rio Branco - AC. Three patients had complications other than rejection. Conclusion: This study offered a great level of knowledge on the reality of patients who were submitted to transplantation in the state of Acre and it may cooperate to the progress of taking care of patient on the waiting list for transplantation and patients in post kidney transplantation.

Keywords: Transplantation; Kidney; epidemiology; complications

\begin{abstract}
AGRADECIMENTOS
Cumpre-me expressar a minha gratidão à equipe da Central de Transplantes do Acre.

Aos Doutores Tércio Genzini, Luciene Pereira de Oliveira, Thadeu Silva de Moura, Yótaro Alberto Camargo Suzuki e

Alonso Castro de Carvalho pelos ensinamentos e conhecimentos partilhados.

Às Enfermeiras Ruth Helena Pimenta Fujimoto e Juliana Leoni Valim pela pronta colaboração no acesso aos dados

necessários à realização deste trabalho.
\end{abstract}

\section{REFERÊNCIAS:}

1. Salmela K, Ahone J, Helsinki, Kootstra G, Maastricht. Renal Transplantation. Atlas of Clinical Transplantation. In: Ari Harjula, Krister Hockerstedt. Copyright (C) Recallmed Ltd., 1995: p.69.

2. Lamb D. Transplante de Orgãos e Ética [Jorge Curbelo trans]. São Paulo: Sociedade Brasileira de Vigilância de Medicamentos/Editora Hucitec, 2000.

3. Marinho A. Estudo sobre as filas para transplante no Sistema Único de Saúde brasileiro. Cad. Saúde Pública. 2006;22(10):2229-39.

4. Bragança RJV. Transplante renal [Internet]. 2008. Disponível em: http://www infonet.com.br/sysinfonet/images/secretarias/Not\%C3\%ADcias/66033/ Hist $\%$ C3\%B3rico\%20de\%20transplante\%20renal.pdf

5. Birtch. Patient selection for renal transplantation. In: C. GT (Ed). Organ Transplantation and Replacement. Philadephia, Lippincot, 1988: p. 262.

6. Steinman TI, Becker BN, Frost AE, Olthoff KM, Smart FW, Suki WN, et al. Guidelines for the referral and management of patients eligible for solid organ transplantation. Transplantation. 2001;71(9):1189-204.

7. Cosio FG, Alamir A, Yim S, Pesavento TE, Falkenhaim ME, Henry ML, et al. Patient survival after renal transplantation: I. The impact of dialysis pretransplant. Kidney Int. 1998;53(3):767-72.

8. Messias E, Skotzko CE. Psychiatric assessment in transplantation. Rev. Saúde Pública. 2000;34(4):415-20.

9. Fine RN. Renal transplantation of the infant and young child and the use of pediatric cadaver kidneys for transplantation in pediatric and adult recipients. Am J Kidney Dis. 1988;12(1):1-10.

10. Fine RN. The adolescent with end-stage renal disease. Am J Kidney Dis 1985;6(2):81-5.

11. Sung RS, Althoen M, Howell TA, Ojo AO, Merion RM. Excess risk of renal allograft loss associated with cigarette smoking. Transplantation. 2001;71(12):1752-7.
12. Johnson DW, Isbel NM, Brown AM, Kay TD, Franzen K, Hawley CM, et al. The effect of obesity on renal transplant outcomes. Transplantation. 2002;74(5):675-81.

13. Weinrauch LA, D'elia JA, Healy RW, Gleason RE, Takacs FJ, Libertino JA, et al. Asymptomatic coronary artery disease: angiography in diabetic patients before renal transplantation. Relation of findings to postoperative survival. Ann Intern Med. 1978;88(3):346-8.

14. Mahony JFC, Pollock RJ. Coronary artery disease is the major late complication of succeful cadaveric renal transplantation. Clin Transplant. 1990;4:129-32.

15. Matas AJ, Simmons RL, Buselmeier TJ, Kjellstrand CM, Najarian JS. Successful renal transplantation in patients with prior history of malignancy. Am J Med. 1975;59(6):791-5.

16. Penn I. Kidney transplantation in patients previously treated for renal carcinomas. Transpl Int. 1993;6(6):350.

17. Stock P, Roland M, Carlson L, Freise C, Hirose R, Terrault N, et al. Solid organ transplantation in HIV-positive patients. Transplant Proc. 2001;33(78):3646-8.

18. Bakir N, Sluiter WJ, Ploeg RJ, van Son WJ, Tegzess AM. Primary renal graft thrombosis. Nephrol Dial Transplant. 1996;11(1):140-7.

19. Rijksen JF, Koolen MI, Walaszewski JE, Terpstra JL, Vink M. Vascular complications in 400 consecutive renal allotransplants. J Cardiovasc Surg. 1982;23(2):91-98.

20. Jordan ML, Cook GT, Cardella CJ. Ten years of experience with vascular complications in renal transplantation. J Urol. 1982;128(4):689-92.

21. Groggel GC. Acute thrombosis of the renal transplant artery: a case report and review of the literature. Clin Nephrol. 1991;36(1):42-5. 
22. Johnson SP, Berry RS. Interventional radiological management of the complications of renal transplantation. Seminars in Interventional Radiology. 2001;18(1):47-58.

23. Bertoni E, Zanazzi M, Rosat A. Efficacy and safety of Palmaz stent insertion in the treatment of renal artery stenosis in kidney transplantation. Tranpl Int. 2000;13(Sup 1):425-30.

24. Gray DWR. Vascular and lymphatic complications after renal transplantation. 5th ed. Philadelphia: Morris PJ Ed Kidney transplantation: principles and practice. WB Saunders, 2001.

25. Hochleitner BW, Kafka R, Spechtenhauser B, Bösmüller C, Steurer W, Königsrainer A, et al. Renal allograft rupture is associated with rejection or acute tubular necrosis, but not with renal vein thrombosis. Nephrol Dial Transplant. 2001;16:124-7.

26. Philipneri M, Solomon H, Garvin PJ, Bastani B. Delayed graft function complicated by spontaneous renal allograft rupture without acute rejection. Am J Nephrol. 2000; 20:71-3.

27. Barker CF, Brayman KL, Markmann JF, Naji A, Olthoff KM. Shaked A. Transplantation of abdominal organs. 16th Ed. Philadelphia: Towsend J CM Ed. Sabiston Textbook of Surgery, WB Saunders, 2001.

28. Korzets A, Ori Y, Zevin D, Weinberger M, Kesslin J, Seror D, et al. Group A streptococcal bacteraemia and necrozitizing faciitis in a renal transplant patient: a case for intravenous immunoglobulin therapy. Nephrol Dial Transplant. 2002;17:150-2.

29. Tang S, Kwok TK, Ho PL, Tang WM, Chan TM, Lai KN. Necrotizing fasciitis in a renal transplant recipient treated with FK 506: the first reported case. Clin Nephrol. 2001;56(6):481-5.

30. Duepree HJ, Fornara P, Lewejohann JC, Hoyer J, Bruch HP, Schiedeck TH Laparoscopic treatment of lymphoceles in patients after renal transplantation. Clin Transplant. 2001;15:375-9.

31. Lipay MAS, Noronha IL, Vidonho Jr A, Romão Jr JE, Campagnari JC, Srougi M. Lymphocele: a possible relationship with acute cellular rejection in kidney transplantation. Sao Paulo Med J. 1999;117(6):238-42.

32. Hobart MG, Streem SB, Gill IS. Renal transplant complications. Minimally invasive management. Urologic Clinic of North America. 2000;27(4):78798.
33. Hayes JM, Streem SB, Graneto D, Hodge EE, Steinmuller DR, Novick AC. Renal transplant calculi: A re-evaluation of risks and management. Transplantation. 1989;47:949-52.

34. El-Mekresh M, Osman Y, Ali-El-Dein B, El-Diasty T, Ghoneim MA. Urological complications after living-donor renal transplantation. BJU International. 2001;87:295-306.

35. Cherchiglia ML, Machado EL, Szuster DAC, Andrade EIG, Acúrcio FA, Caiaffa WT, et al. Epidemiological profile of pacientes on renal replacementtherapy in Brazil, 2000-2004.Rev Saúde Pública. 2010;44:63949.

36. Cunha CB, León ACP, Schramm JMA, Carvalho MS, Souza Júnior PRB, Chain R. Tempo até o transplante e sobrevida em pacientes com insuficiência renal crônica no Estado do Rio de Janeiro, Brasil, 1998-2002. Cad. Saude Pública, Rio de Janeiro, abr, 2007(abr);23:805-13.

37. Sesso R. Epidemiologia da Insuficiência Renal Crônica no Brasil. Guia de Nefrologia. Ajzen H, Schor N, Ed. Manole, São Paulo, 2002, 1-7.

38. Santos PR. Relação do sexo e da idade com nível de qualidade de vida em renais crônicos hemodialisados. Rev Assoc Med Bras. 2006;52(2):356-9.

39. Morsch C, Gonçalves LF, Barros E. Índice de gravidade da doença renal, indicadores assistenciais e mortalidade em pacientes em hemodiálise. Rev Assoc Med Bra. 2005;51(5):296-300.

40. D’Ávila R, Guerra EMM, Rodrigues CIS, Fernandes FA, Cadaval RAM, Almeida FA. Sobrevida de pacientes renais crônicos em diálise peritoneal e hemodiálise. J Bras Nefrol. 1999;21(1):13-21.

41. Machado EL, Leal CM, Acúrcio FA. Perfil e desfecho clínico de pacientes em lista de espera por transplante renal, Belo Horizonte (MG, Brasil), 20002005. Ciência \& Saúde Coletiva. 2011;16(3):1981-92.

42. Lopes JAM, Almeida CJR, Hachul M, Srougi M. Frequência de estenose de artéria renal em 676 transplantes renais. Rev Ass Med Brasil. 1998;44(3):210-

43. Cassini MF. Sobrevida de alotransplante renal com doador cadáver relacionada à idade do doador, tempo de isquemia fria e compatibilidade HLA [Dissertação de Mestrado]. Faculdade de Medicina de Ribeirão Preto, 2009.

44. Sociedade Brasileira de Nefrologia. Transplante renal: complicações cirúrgicas. Rev Assoc Med Bras. 2007;53(3):189-207. 